\title{
CONVERGENCIAS ENTRE LOS ENFOQUES ETOLÓGICO-LINGÜÍSTICO Y PRAGMÁTICO-SOCIOCULTURAL
}

\begin{abstract}
Resumen. El propósito del presente estudio es exponer las afinidades de dos enfoques sistemáticos de indagación de las relaciones entre los usos lingüísticos y la respectiva cultura, a saber: el etológico-lingüístico y el pragmático-sociocultural. Ambos poseen una similar concepción de la cultura y la sociedad y, además, una metodología con varios principios compartidos, aunque mantienen diferencias teóricas distintivas en los conceptos abarcados y en las abstracciones derivadas de los fenómenos observados en la realidad. La comparación de algunas convergencias teóricas se realiza sobre la base de investigaciones acerca de formas de tratamiento del mundo hispánico, tuteo / voseo y ustedeo.
\end{abstract}

Palabras clave: enfoque etológico-lingüístico, enfoque pragmático-sociocultural, 213 convergencias teóricas, convergencias metodológicas.

\section{Introducción}

El propósito del presente estudio es exponer afinidades entre dos enfoques, el etológico-lingüístico y el pragmático-sociocultural que abordan la cultura a través de la interacción verbal. Ambos comparten una misma concepción de cultura y sociedad, además de coincidir en varios principios metodológicos, aunque cada uno de ellos mantiene sus diferencias teóricas en los conceptos abarcados y en las abstracciones derivadas de los fenómenos observados en la realidad. Se comparan algunas convergencias teóricas a partir de los siguientes artículos referentes a formas de tratamiento del mundo hispánico: «Sobre los motivos del empleo de tú y usted de estudiantes universitarios en Guadalajara (Jalisco, México) desde la perspectiva de los enfoques socio y etológico-lingüísticos» de Nowikow (2010), por una parte, y «Voseo, ustedeo y cortesía verbal en folletos de propaganda argentinos» de

\footnotetext{
* Universidad Nacional de Río Cuarto.
} 
Kaul de Marlangeon (2010) y «Voseo / ustedeo argentinos. Su variación pragmática intralingüe e intracultural» de Kaul de Marlangeon (2011), por la otra.

Siguiendo los principios de la etología o ciencia que estudia los diferentes modos de comportamiento del hombre y, en consonancia con el pensamiento de Hall (1959: 186), para quien la cultura es comunicación y, recíprocamente, la comunicación es cultura, Nowikow (2003, 2005a, 2005b, 2006 y 2010) expone su propio enfoque que denomina etológicolingüístico, apoyado también en los estudios semánticos, transculturales y contrastivos de Wierzbicka (2003), en el marco de la etnografía de la comunicación de Hymes (1972) y en la etnopsicología (Díaz Guerrero, 2001).

Ese enfoque etológico-lingüístico tiene la finalidad de abordar los lazos existentes ente estilos comunicativos y recursos lingüísticos, y su correspondencia con las normas culturales que regulan el comportamiento social de los hablantes. Por ello se ocupa de la descripción e interpretación de las diferencias entre lenguas y de los comportamientos verbalizados de esas diferentes comunidades lingüísticas. A tal fin, aboga por investigaciones, tanto de pragmática transcultural (dedicada al estudio de diferentes actos de habla en diversas comunidades lingüísticas y socioculturales) como de pragmática interlingüística (abocada a examinar destrezas y conocimientos pragmalingüísticos adquiridos en el proceso de aprendizaje de una segunda lengua).

Por su parte, el enfoque pragmático-sociocultural (Bravo, 1999, 2004 y 2009; Hernández Flores, 2013; Kaul de Marlangeon, 2005, 2008, 2014, 2017, entre otros) se aplica al análisis discursivo de actividades de imagen, roles, premisas culturales, identidades, ideologías, intenciones, estrategias y efectos sociales de las interacciones en el contexto de los hablantes, es decir, se emplea para la descripción del uso situado de los recursos comunicativos provistos por una lengua determinada dentro de su propio sistema sociocultural relacionando lo lingüístico con lo social. El enfoque pragmático-sociocultural constituye un marco teórico y metodológico apropiado para el análisis de la (des)cortesía verbal.

Tanto la cortesía como la descortesía en cuanto manifestaciones de la conducta social son fenómenos sensibles al contexto situacional y cultural y, por ende, están inmersos en una determinada sociedad y cultura. La cortesía es un principio regulador del equilibrio social y la descortesía significa un quiebre de tal equilibrio. Cortesía y descortesía están vinculadas al asunto vital y perenne de cómo la persona desea verse y ser vista por los demás, de cómo trata a los otros y cómo desea ser tratada por ellos y ésta es la causa por la cual el estudio de la imagen o face (Goffman, 1967), va unido al de 
la (des)cortesía. Generalmente, para evitar la vulnerabilidad mutua de sus imágenes, los participantes de una interacción se esfuerzan por mantener relaciones sociales estables.

Cortesía y descortesía sirven a las relaciones humanas y su meta es, respectivamente, para la cortesía, prevenir o reparar el posible daño producido por un acto amenazador de imagen y, para la descortesía, incrementar la amenaza sin reparación de imagen.

La noción de imagen resulta el medio pertinente para explicar las manifestaciones corteses o descorteses porque es constitutiva de la interacción y solamente es posible cifrar la amenaza de imagen de un determinado tipo de acto de habla en su respectivo contexto de cultura.

\section{Aspectos metodológicos compartidos para el estudio del lenguaje en uso}

2.1. Ambos enfoques sostienen la necesidad de evitar sesgos etnocentristas en la investigación que puedan acarrear una defectuosa interpretación de los comportamientos lingüísticos bajo estudio por parte del analista. De este modo, los enfoques están en consonancia con la postura de Janney y Arndt (1993), quienes abogan por un relativismo moderado que sirva de marco teórico culturalmente imparcial.

2.2. Otro principio metodológico compartido por los enfoques referidos es que las normas socioculturales son las que presiden los estilos discursivos. En relación con ello, únicamente es posible analizar un determinado tipo de acto de habla en su respectivo contexto de cultura, pues la cultura es el más amplio contexto de interpretación de la actividad humana.

2.3. Ambos enfoques coinciden en abordar el objeto de estudio desde la multidisciplinariedad. En los usos lingüísticos como fenómenos observables confluyen aspectos que incumben a otras disciplinas. Así para la relación entre los comportamientos comunicativos y factores de orden social ambos enfoques se valen de la etnografía de la comunicación, la etnometodología lingüística y la sociolingüística interaccional. Asimismo, la investigación suele tomar aspectos de la psicología social para las normas de convivencia y la resolución de conflictos, la sociología para la interacción de los grupos sociales y la antropología cultural para las estructuras sociales y diversidad de expresiones culturales y lingüísticas, como así también de la psicología transcultural, especialmente la etnopsicología. 
2.4. Las unidades de análisis, en uno u otro enfoque, no son las personas como ocurre en otras ciencias sociales, sino unidades lingüísticas (textos, actos, estrategias) y unidades extralingüísticas (comunidades de habla o comunidades de práctica cortés o descortés).

2.5. Ambos enfoques se complementan con la elección de procedimientos investigativos cualitativos para estudiar discursos como prácticas sociales.

2.6. Los hechos investigados en uno y otro enfoque son básicamente comportamientos, pues se proponen analizar los usos lingüísticos de acuerdo con las normas culturales que rigen tales comportamientos sociales.

2.7. Ambos enfoques indagan la intersección entre el lenguaje y la realidad social para observar cómo se construye el mundo social: el enfoque etológico-lingüístico integra el estudio de los comportamientos verbales con el de los estilos discursivos de los hablantes y de las normas culturales atinentes. Por su parte, los hechos estudiados en el enfoque sociocultural son conductas, intenciones y efectos sociales de (des) cortesía. Tales hechos se consideran en el sistema de relaciones del que forman parte, es decir, en su contexto y por su función y finalidad. Es por ello que el contexto natural tiene primacía como elemento esencial de la investigación, fundada en el análisis del discurso de textos reales, desechando el análisis de enunciados aislados.

\section{Aspectos teóricos compartidos, a través de la comparación de estudios sobre las formas de tratamiento del tuteo / voseo / ustedeo del español}

El enfoque etológico-lingüístico apela a dos conceptos básicos, por un lado, a los modelos etológico-lingüísticos (MEL) y por el otro, a las entidades de cultura lingüísticamente operacionales (ECLO).

Los MEL «funcionan como mecanismos subyacentes de la organización del discurso» (Nowikow, 2005a: 187 y sgtes.) y su desempeño se aprecia en el marco de un análisis transcultural o interlingüístico para la codificación y decodificación cultural, aunque son también observables entre comunidades socioculturalmente semejantes.

Los modelos etológico-lingüísticos o patrones comportamentales verbalizados están organizados sobre la base de tres dimensiones: social, que abarca las normas subyacentes en una determinada sociedad, etológica, 
que comprende los modos de reacción humana manifestados a través de la conducta, y lingüística, que incluye actos de habla utilizados que se hallan en correspondencia con diferentes tipos de comportamiento.

Las ECLO son «fenómenos o conceptos relacionados con la cultura material o espiritual que, de alguna manera influyen en la selección y uso de determinadas formas y estructuras linguisticas» (Nowikow, 2005a: 185-186), el autor ejemplifica con la diferente conceptualización para la realización de los saludos: en función del concepto de "luz solar" en Polonia y de "horas de comer" en España.

Las entidades de cultura ECLO aplicadas por Nowikow (2010) en el análisis de las formas de tratamiento sirven para explicar las motivaciones de la selección de dichas formas pronominales por parte de hablantes mexicanos, es decir, para dar cuenta de la incidencia de factores socioculturales que promueven en tales hablantes la respectiva selección del tú o del usted. Identifica cuatro clases básicas de ECLO prevalecientes en la encuesta realizada a tal fin en la ciudad de Guadalajara entre enero y mayo de 2005, con 129 informantes: a) comportamiento habitual (norma individual); b) factor de profesión (norma empresarial); c) edad (visiones objetiva y subjetiva) y d) factor del extranjero. Llega a varias conclusiones: 1) que las ECLO que suscitan el tuteo son los factores de "edad" y "visión subjetiva de la persona joven"; 2) que la difusión cada vez más grande del tú en detrimento del usted se debe a cambios socioculturales globales caracterizados por su tendencia al igualitarismo en las sociedades; 3 ) que en las sociedades modernas se propaga el tuteo psicológico impuesto por el lenguaje de la publicidad y 4) la posible influencia de otras lenguas, a través, por ejemplo, de traducciones de películas.

Estos tipos de lazos entre las convenciones culturales o pautas de comportamiento de un determinado grupo en una situación particular para la selección de un determinado uso lingüístico son abordados en el enfoque socio-cultural como premisas culturales (Bravo, 1999) que el análisis de la (des) cortesía verbal intenta desentrañar y exhibir.

En el trabajo de Kaul de Marlangeon (2010) se analiza la alternancia de vos / usted en un mismo texto para observar cómo su uso está condicionado por la fuerza de cortesía que estas formas portan en la dinámica discursiva. En los folletos de propaganda del sector servicios analizados, el uso de vos argentino (equivalente al tú de otros ámbitos hispánicos) se sostiene en la premisa cultural, es decir, el conocimiento de la convención social de trato amistoso como garantía de confianza o de trato amistoso como señal de reconocimiento grupal, mientras que el uso de usted está plasmado por la apelación a la formalidad para el trato con personas distinguidas o para propender al complimiento de compromisos. Este artículo se completa en 
Kaul de Marlangeon (2011) para abarcar también otros usos y la variación pragmática en el campo de la descortesía. En el ámbito de la cortesía se registran otros empleos como cambio del propósito estratégico del emisor; titubeo en el trato; adecuación a la situación comunicativa; afiliación a la nacionalidad en un medio foráneo; mitigación de la descortesía. En el campo de la descortesía aparecen diversas motivaciones: ruptura de la expectativa respecto del trato; motivación ideológica; represalia por instauración de lo absurdo o por una agresión sorpresiva del interlocutor.

Aunque el empleo del metalenguaje sea privativo de cada visión teórica, por lo cual ya se aborden entidades de cultura o bien premisas culturales, ambos enfoques se centran en el análisis de los valores culturales vigentes en una determinada sociedad reflejados en empleo y selección de determinadas formas lingüísticas. Luego tales entidades o premisas sirven como instrumento del análisis porque hacen referencia explícita al conocimiento que el investigador supone compartido por los hablantes. Éstos no son del todo conscientes de la influencia que ejercen sus creencias y valores culturales en la producción y en la interpretación de sus comportamientos verbales. Es por ello que el analista no solo exhibe su análisis particular, sino que además lo comprueba objetivamente mediante la aplicación de encuestas, test de hábitos sociales o metodología de consultación.

La importancia de las ECLO o de las premisas culturales es volverlas explícitas en la investigación y corroborarlas, so pena de correr el riesgo de caer en interpretaciones etnocentristas.

\section{Conclusiones}

Los enfoques presentados, con sus similitudes y diferencias, constituyen herramientas teóricas y metodológicas apropiadas para explorar los comportamientos lingüísticos en la cultura, pues ambos emplean procesos sistemáticos para la contextualización e interpretación del discurso en una determinada lengua y sociedad.

Reconociendo las naturales diferencias teóricas entre dichos enfoques, ellos ofrecen los recursos para examinar la cultura como una compleja red de relaciones de valores, creencias, convenciones sociales y percepciones subjetivas compartidas entre los hablantes que el analista se encarga de desentrañar. 
Tanto el enfoque etológico como el pragmático sociocultural permiten abordar con éxito el examen de hechos lingüísticos pragmáticosocioculturales de la lengua española y de otras lenguas.

En uno de los comentarios de las conclusiones (Nowikow, 2005a: 193), este autor explica que «El enfoque etológico-lingüístico es un modelo de investigación en plena evolución. De ahí que su marco teórico esté abierto a nuevos conceptos y soluciones». Análoga aseveración cabe para el enfoque pragmático-sociocultural; en efecto, ambas perspectivas se proponen la comprensión más clara y precisa de los fenómenos que estudian.

\section{Bibliografía}

BRAVO, D. (1999). «¿Imagen 'positiva' vs. imagen 'negativa'? Pragmática sociocultural y componentes de face», Oralia, 2, 155-184.

BRAVO, D. (2004). «Tensión entre universalidad y relatividad en las teorías de la cortesía», en D. BRAVO y A. BRIZ (eds.), Pragmática sociocultural: estudios sobre el discurso de cortesía en español. Barcelona: Ariel Lingüística, 15-38.

BRAVO, D. (2009). «Pragmática, sociopragmática y pragmática sociocultural del discurso de la cortesía. Una introducción», en D. BRAVO, N. HERNÁNDEZ FLORES, y A. CORDISCO (eds.), Aportes pragmáticos, sociopragmáticos y socioculturales a los estudios de la cortesía en español, vol. 2, Buenos Aires: Programa EDICE-Dunken, 31-68.

DÍAZ GUERRERO, R. (2001). Psicología del mexicano. Descubrimiento de la etnopsicología. México: Editorial Trillas.

GOFFMAN, I. (1967). Interactional Ritual: Essays on face-to-face behavior. Doubleday: Anchor Books.

HALL, E. T. (1959). The Silent Language. New York: Doubleday.

HERNÁNDEZ FLORES, N. (2013). «Actividad de imagen: caracterización y tipología de la interacción comunicativa», Soprag, 1(2): 175-198.

HYMES, D. H. (1972). «Models of the interaction of language and social life», en J. J. GUMPERZ y D. HYMES (eds.), Directions in sociolinguistics: The ethnography of communication. New York: Holt, Rinehart \& Winston, 35-71.

JANNEY, R. W. y ARNDT, H. (1993). «Universality and relativity in cross-cultural research: A historical perspective», Multilingua, 12/1, 13-50.

KAUL DE MARLANGEON, S. (2005). «Descortesía de fustigación por afiliación exacerbada o refractariedad» (cap. 11), en D. BRAVO (ed.), Estudios de la (des) cortesía en español. Categorías conceptuales y aplicaciones a corpora orales y escritos, vol. I. Buenos Aires: Programa EDICE-Dunken, 299-318.

KAUL DE MARLANGEON, S. (2008). «Tipología del comportamiento verbal descortés en español», en A. BRIZ-GÓMEZ, A. HIDALGO-NAVARRO, 
M. ALBELDA MARCO, J. CONTRERAS y N. HERNÁNDEZ FLORES (eds.), Cortesía y conversación: de lo escrito a lo oral. Tercer Coloquio Internacional del Programa EDICE, vol. 3. Valencia / Estocolmo: Universidad de Valencia-Programa EDICE, 254-266.

KAUL DE MARLANGEON, S. (2010). «Voseo, ustedeo y cortesía verbal en folletos de propaganda argentinos», en M. HUMMEL, B. KLUGE y M. E. VÁZQUEZ LASLOP (eds.), Formas y fórmulas de tratamiento en el mundo hispánico. México, D.F. / Graz: El Colegio de México / Karl-Franzens-Universitât, 993-1011.

KAUL DE MARLANGEON, S. (2011). «Voseo / ustedeo argentinos. Su variación pragmática intralingüe e intracultural», en C. GARCIA y M. E. PLACENCIA (eds.), Estudios de variación pragmática en español. Buenos Aires: Dunken, 217-241.

KAUL DE MARLANGEON, S. (2014). «Delimitación de unidades extralingüísticas de análisis del discurso de (des)cortesía». Signo y Seña (Revista del Instituto de Lingüística de la Universidad de Buenos Aires), 26, 7-22.

KAUL DE MARLANGEON, S. (2017). «Tipos de descortesía verbal y emociones en contextos de cultura hispanohablante», Soprag, 5 (1): 1-23.

KERBRAT-ORECCHIONI, C. (2004). «¿Es universal la cortesía?», en D. BRAVO y A. BRIZ (eds.), Pragmática sociocultural: estudios sobre el discurso de cortesía en español. Barcelona: Ariel Lingüística, 39-53.

NOWIKOW, W. (2003). «Sobre los modelos etológico-lingüísticos», en B. ŁUCZAK, A. GREGORI I GOMIS, A. LÓPEZ GONZÁLEZ y J. WACHOWSKA (eds.), El enfoque social y cultural en los estudios lingüísticos y literarios. Poznań: Universidad Adam Mickiewicz, 155-162.

NOWIKOW, W. (2005a). «El enfoque etológico-lingüístico desde la perspectiva de las pragmáticas transcultural e interlingüística», Lodz Papers in Pragmatics, 179-195.

NOWIKOW, W. (2005b). «Sobre la transmisión de la información en los contactos interculturales: un estudio contrastivo entre el español de México y el polaco», en J. MURILLO MEDRANO (ed.), Actas del II Coloquio Internacional del Programa EDICE. Actos de habla y cortesía en distintas variedades del español. Perspectivas teóricas y metodológicas. San José de Costa Rica: Universidad de Costa Rica-Programa EDICE, 407-418.

NOWIKOW, W. (2006). «Sobre algunos conceptos básicos de la lingüística etológica», en M. SCHRADER-KNIFFKI (ed.), La cortesía en el mundo hispánico. Nuevos contextos, nuevos enfoques metodológicos. Madrid / Frankfurt am Main: Iberoamericana / Vervuert, 183-190.

NOWIKOW, W. (2010). «Sobre los motivos del empleo de tú y usted de estudiantes universitarios en Guadalajara (Jalisco, México) desde la perspectiva de los enfoques socio y etológico-lingüísticos», en M. HUMMEL, B. KLUGE y M. E. VÁZQUEZ LASLOP (eds.), Formas y fórmulas de tratamiento en el mundo hispánico. México, D. F. / Graz: El Colegio de México / Karl-Franzens-Universitât, 785-807.

WIERZBICKA, A. (2003). Cross-Cultural Pragmatics: the Semantics of human interaction. Berlin-New York: Mouton de Gruyter. 